\title{
Effects of microwave on extracellular vesicles and microRNA in milk
}

\author{
Zhehao Zhao, ${ }^{1}$ Siran Yu, ${ }^{1}$ Minjing Xu, and Ping $\mathrm{Li}^{2}$ \\ Research Center for Translational Medicine at Shanghai East Hospital, School of Life Science and Technology, Tongji University, Shanghai, \\ 200092, PR China
}

\section{ABSTRACT}

This study demonstrates the effects of microwaves on the microRNA (miRNA) content of milk and milk extracellular vesicles (EV). We determined the miRNA concentration in milk subjected to different treatments using real-time PCR and a spectrophotometer. The miRNA expression and total RNA content of the microwaved milk samples were lower when compared with untreated milk. We measured the microstructure and the size distribution by scanning electron microscopy and dynamic light scattering to verify the loss of miRNA in microwaved milk due to damage to the $\mathrm{EV}$. The results revealed that 2 different-sized EV were present and had an average size of 147.50 and 22.14 $\mathrm{nm}$, respectively. Furthermore, acridine orange staining showed that the total RNA content in microwaved milk EV was lower than that in cow milk. These results suggest that EV may confer the protection and the stability of the miRNA in milk.

Key words: milk RNA, microRNA, extracellular vesicles, microwave

\section{INTRODUCTION}

MicroRNA (miRNA) are small, noncoding RNA that were first discovered in 1993 in Caenorhabditis elegans (Lee et al., 1993), which have been recognized as playing a crucial role in a wide range of physiological processes, including developmental timing (Lee and Ambros, 2001), cell proliferation and apoptosis (Boon et al., 2013), and immune response (Rodriguez et al., 2007). Moreover, the deregulation of miRNA is associated with aberrant cell functions leading to cancers (Calin and Croce, 2006; Esquela-Kerscher and Slack, 2006) and other diseases (Lu et al., 2008), whereas the mechanism of communication between cells was not

\footnotetext{
Received September 20, 2016.

Accepted December 28, 2016.

${ }^{1}$ These authors contributed equally to this work.

${ }^{2}$ Corresponding author: liping01@tongji.edu.cn
}

clear at that time. Subsequently, evidence has revealed that the transfer of miRNA between cells, and even between distal tissues, is typically mediated by extracellular vesicles $(\mathbf{E V})$, which are small membrane vesicles of endocytic origin that are released into the extracellular environment as a result of the fusion of multivesicular bodies with the plasma membrane (Valadi et al., 2007). Electron micrographs have revealed that EV are rounded structures with a size of approximately 40 to $100 \mathrm{~nm}$ (van der Pol et al., 2012). MicroRNA packaged in EV have been found in 12 different human bodily fluids including breast milk (Weber et al., 2010). Hata et al. (2010) isolated microvesicles with a diameter of approximately $100 \mathrm{~nm}$ from bovine milk and found that the majority contained miRNA. In the same year, a Chinese research group systematically screened miRNA expression and identified 245 miRNA in raw milk (Chen et al., 2010a). Furthermore, they also suggested that 7 milk-specific miRNA could serve as novel indicators and possibly as a new standard for the quality control of raw milk and milk-related commercial products (Chen et al., 2010a). Recently, it has also been reported that murine (Izumi et al., 2014) and porcine (Gu et al., 2012; Chen et al., 2014) milk contains miRNA.

Data from several studies imply that milk miRNA carried by EV are not degraded because they are protected by the lipid bilayer of the EV (Izumi et al., 2012; Baier et al., 2014). Previously, Izumi et al. (2012) found that miRNA were stable at $37^{\circ} \mathrm{C}$, at low $\mathrm{pH}$, and in the presence of RNase; conversely, they were not resistant to treatment with the detergent $1 \%$ Triton X-100 (Nacalai Tesque, Kyoto, Japan). Similar results have been reported in which EV derived from commercial milk were not susceptible to degradation by low $\mathrm{pH}$ or boiling or freezing treatments, thereby confirming the stability of EV (Pieters et al., 2015). The literature also indicates that EV derived from commercial milk can withstand harsh treatment, such as pasteurization (Pieters et al., 2015). Pasteurization is a conventional process applied to milk to inactivate pathogenic bacteria. Pasteurization via a microwave has many advantages: it is time-saving, uses energy effectively, and is convenient (Dehghan et al., 2012; Salazar-Gonzalez 
et al., 2012; Chandrasekaran et al., 2013). Nonetheless, Howard et al. (2015) heated milk with different fat levels in a microwave for $15 \mathrm{~s}$ and detected a $40 \%$ loss of miR-29b but no significant loss of miR-200c. Those authors speculated that the decrease in miR-29b occurred due to the disruption of the exosomal membrane; however, few investigations have been conducted to substantiate their hypothesis. Despite microwaving apparently destroying EV by denaturing surface proteins, direct damage to the miRNA during microwaving cannot be excluded without experimental verification. Other studies have established that microwaving affects the yield and integrity of DNA (Musto et al., 2014), which could be another reason for the loss of miRNA during microwaving. As previously mentioned, the effects of different treatments on EV have received little attention, thus undervaluing the connection between miRNA and EV. Our study intended to explain how microwaves irreparably damage miRNA in milk by using a series of experiments on EV. We used scanning electron microscopy and a new method, dynamic light scattering (DLS), to observe the microstructure as well as the size distribution of EV derived from milk (Sokolova et al., 2011). Simultaneously, we used another new method, monitoring the EV RNA content using acridine orange staining to assess the effects of microwaving. Finally, we used quantitative PCR (qPCR) to analyze miRNA expression to determine the changes resulting from the different treatments. In this way, we could complement prior research by identifying the relationship between EV and miRNA and add to the body of knowledge about the effects of milk processing on milk quality.

\section{MATERIALS AND METHODS}

\section{Milk Samples and Different Treatment Methods}

Milk from Holstein cows was sampled. All fresh milk samples were provided by the Bright Dairy and Food Co. Ltd. (Shanghai, China) and all cows were in good health. Milk samples were transported to the laboratory on ice and placed in sterile $1,500-\mathrm{mL}$ bottles. Normal, untreated milk was stored at $4^{\circ} \mathrm{C}$ for further study.

Defatted milk (40 mL) was prepared by centrifugation twice at $7,000 \times g$ and $4^{\circ} \mathrm{C}$ for $30 \mathrm{~min}$ with a refrigerated centrifuge (Universal 320R, Hettich, Kirchlengern, Germany). Microwave milk (40 mL) was heated in a $100-\mathrm{mL}$ glass flask in a $700-\mathrm{W}$ microwave oven (HR-6703D, Haier, Qingdao, China) for $32 \mathrm{~s}$ to boiling. The microwave oven internal volume was 10.62 $\mathrm{L}$ with dimensions of $190 \times 302 \times 185 \mathrm{~mm}$. Before heating the milk sample, we determined the real power by microwaving water 3 times. The real power was $304.92 \pm 7.64 \mathrm{~W}($ mean $\pm \mathrm{SD})$.

As a positive control, 2\% Triton X-100 was added to a $40-\mathrm{mL}$ milk sample and treated as previously described (Izumi et al., 2012). All treated milk samples were used for RNA isolation and other experiments immediately, and the remainder was stored at $-20^{\circ} \mathrm{C}$ for further analysis. All treatments were repeated for 3 independent experiments.

\section{Isolation of EV}

The EV were isolated using a previously described method (Mrvar-Brecko et al., 2010; Hata et al., 2010; Chen et al., 2014). Fresh milk samples were centrifuged 3 times at $4^{\circ} \mathrm{C}$ for 30 min each at 300, 1,500, and 7,000 $\times g$ to remove cells, large debris, and fat, respectively. A defatted supernatant was prepared by ultracentrifugation (Avanti J-25, Beckman Coulter, Brea, CA) at 500,000 and $70,000 \times g$ for $1 \mathrm{~h}$ at $4^{\circ} \mathrm{C}$, followed by sequential filtration through 0.45 - and $0.22-\mu \mathrm{m}$ filters to obtain solutions of EV for further analysis.

\section{Scanning Electron Microscopy}

The EV solutions were fixed with $3.7 \%$ glutaraldehyde in PBS for $24 \mathrm{~h}$ at $4^{\circ} \mathrm{C}$, followed by washing with PBS for $10 \mathrm{~min}$. Next, the samples were dehydrated in an ethanol series $(50,60,70,80,90$, and 99\%). The samples were maintained in contact with each solution for $10 \mathrm{~min}$. Finally, the samples were air-dried for at least $24 \mathrm{~h}$, mounted on aluminum stubs, and gold-plated before viewing with a scanning electron microscope (S-4800, Hitachi, Tokyo, Japan) operating at $3.0 \mathrm{kV}$.

\section{DLS}

The size distribution was determined using a Zetasizer range (Nano-ZS 90, Malvern Instruments, Malvern, UK) with the general settings at $25^{\circ} \mathrm{C}$. The size distribution of $\mathrm{EV}$ is related to the intensity of the light scattered by each particle. All of the EV were diluted 1:1,000 with PBS before DLS analysis.

\section{Acridine Orange Staining}

Approximately $10 \mu \mathrm{L}$ of dye mixture $(100 \mathrm{mg} / \mathrm{mL}$ of acridine orange in PBS) was mixed with $500 \mu \mathrm{L}$ of EV. After incubation for $30 \mathrm{~min}$ at room temperature, the fluorescence was analyzed with a Multi-Mode Microplate Reader (SpectraMax M5, Molecular Devices, Sunnyvale, CA) using 488-nm excitation and 650-nm emission wavelengths. 


\section{RNA Extraction}

Total RNA was extracted from extracellular vesicles using the Trizol LS Reagent (Invitrogen, Carlsbad, $\mathrm{CA}$ ) according to the manufacturer's protocol. Briefly, $250-\mu \mathrm{L}$ samples were mixed well with 3 volumes of Trizol LS, followed by incubation for $5 \mathrm{~min}$ at room temperature. Next, $200 \mu \mathrm{L}$ of chloroform was added to the homogenate, which was mixed thoroughly by vortexing, incubated for $15 \mathrm{~min}$ at room temperature, and centrifuged $\left(12,000 \times \mathrm{g}, 4^{\circ} \mathrm{C}, 15 \mathrm{~min}\right)$. The resulting aqueous phase was transferred to another tube, $500 \mu \mathrm{L}$ of isopropanol was added, the tube was incubated for $10 \mathrm{~min}$ at room temperature, and centrifuged $(12,000$ $\left.\times g, 4^{\circ} \mathrm{C}, 10 \mathrm{~min}\right)$ again. The precipitate was resuspended in $75 \%$ ethanol and centrifuged $\left(7,500 \times g, 4^{\circ} \mathrm{C}\right.$, $5 \mathrm{~min}$ ). The air-dried RNA was finally eluted with 30 $\mu \mathrm{L}$ of RNase-free water, and its concentration was determined with a spectrophotometer (NanoVue PLUS, GE Healthcare, Pittsburgh, PA).

\section{$q P C R$}

Quantitative PCR was performed using an ABI PRISM 7500 (Applied Biosystems, Waltham, MA). Briefly, $200 \mathrm{ng}$ of miRNA was reverse transcribed using the miRcute miRNA First-Strand cDNA Kit (Tiangen, China). Quantitative PCR was performed with the miRcute miRNA qPCR Detection Kit (Tiangen, China). The reaction solution was prepared on ice and was composed of $10 \mu \mathrm{L}$ of $2 \times$ miRcute miRNA Premix, $0.4 \mu \mathrm{L}$ of PCR forward primer $(10 \mu M), 0.4 \mu \mathrm{L}$ of PCR reverse primer $(10 \mu M), 2 \mu \mathrm{L}$ of cDNA, and doubledistilled $\mathrm{H}_{2} \mathrm{O}$ to a final volume of $20 \mu \mathrm{L}$. The following qPCR program was used: initial activation $\left(94^{\circ} \mathrm{C}\right.$, $2 \mathrm{~min})$, followed by 40 to 45 cycles of denaturation $\left(94^{\circ} \mathrm{C}, 20 \mathrm{~s}\right)$, and extension $\left(60^{\circ} \mathrm{C}, 34 \mathrm{~s}\right)$. All reactions were performed in triplicate. The forward primers for the miRNA had the same sequences as the Bos taurus miRNA, and the melting temperature value of all of the forward primers was adjusted to $65^{\circ} \mathrm{C}$ by following the manufacturer's instructions. The forward primers sequences were: miR-200c $=5$ '-GGTAATACTGCCGGGTAATGATGGA-3'; miR-21 = 5'-GGGTAGCTTATCAGACTGATGTTGACTAA- $3^{\prime} ; \quad$ miR-29b = 5'-GGGTAGCACCATTTGAAATCAGTGTTA-3' .

\section{Statistical Analysis}

Data are expressed as the mean \pm standard error of the mean. Multiple comparisons were performed using one-way ANOVA. The statistical analysis was performed using Origin 8.0 (OriginLab Corporation,
Northampton, MA). All data are representative of 3 independent experiments.

\section{RESULTS}

\section{Cycle Threshold of miR-200c in Milk Samples After Treatment}

The mean cycle threshold $(\mathbf{C t})$ value of miR-200c in microwaved milk was higher than in the other treatments, including pressure, agitation, freezing, and untreated milk, indicating that the RNA concentration in the microwaved milk was lower than in the other treated milk samples (Figure 1).

\section{RNA Concentration in Different Milk Samples}

The total RNA concentrations were $23.69 \pm 1.71$, $20.56 \pm 1.5,9.89 \pm 1.55$, and $12.09 \pm 2.41 \mathrm{ng} / \mu \mathrm{L}$ in untreated milk, defatted milk, microwaved milk, and milk treated with Triton X-100, respectively (Figure 2). The RNA concentrations in the normal and defatted milk were higher than those in the microwaved milk and the milk treated with Triton X-100, indicating a reduction of RNA content in milk after treating with microwave and Triton X-100.

\section{Effect of Microwaving on Milk miRNA Concentration}

In Figure 3A, the Ct values of miR200c and miR-21 in microwaved milk were higher than those in normal milk; however, the Ct value of miR-29b was the same in all 3 samples, indicating that the concentration of miR-200c and miR-21 in microwaved milk was lower (96.13 and $90.01 \%$, respectively) than that in untreated milk. No significant difference in miR-29b was noted in any of the 3 samples.

To determine the reason for the lower miRNA levels, we boiled the milk samples with a microwave or an alcohol lamp and determined the RNA level with realtime PCR; the results are shown in Figure 3B. When the milk samples were boiled either with a microwave or an alcohol lamp, the Ct values of miR-200c were lower than in normal milk. However, when the milk samples were cooled for 30 min to room temperature after microwaving, the mean $\mathrm{Ct}$ value was higher than when they were hot. No significant difference in miR$29 \mathrm{~b}$ was noted in any sample.

Figure 3C shows the $\mathrm{Ct}$ values of miR-200c and miR-29b in EV of microwaved and untreated milk. For miR-200c, the mean Ct values of microwaved milk EV were higher than for the untreated milk EV; however, no significant differences in miR-29b were noted in 
any milk EV samples. Therefore, the concentration of miR-200c in microwaved milk EV was lower than in untreated milk EV. For miR-200c and miR-29b, the results showed the same trend in the milk (Figure 3A) and milk EV samples (Figure 3C).

\section{Scanning Electron Microscopy Results of EV from Milk}

Two different structures were seen in the milk EV samples, with an average diameter of $21.67 \pm 6.41$ and $138.47 \pm 21.80 \mathrm{~nm}$, respectively. (Figure 4); both structures were globular. The picture has a $500-\mathrm{nm}$ scale for 10 grids and a magnification of 60,000 fold.

\section{DLS Results of EV from Milk Samples}

The DLS results show that 2 different-sized structures are present in the milk EV samples. The average diameters of the 2 structures in the milk EV samples are 22.14 and $147.50 \mathrm{~nm}$; in addition, the light intensities are 3.3 and $96.7 \%$ (Figure 5). The quality of the results from the instrument was good.

\section{Acridine Orange-Stained EV from Milk Samples}

The results of the concentration gradient experiment with the EV are shown in Figure 6A. The milk EV were diluted to different concentrations $(540,270,108,54$, 21.6 , and $10.8 \mu \mathrm{g} / \mathrm{mL}$ ) for standard curve analysis. The average fluorescence intensities (arbitrary units; AU) of the different concentrations were $448.70 \pm 6.52,375.42$ $\pm 5.55334 .15 \pm 12.09,313.00 \pm 5.86,301.16 \pm 2.86$, and $294.80 \pm 7.56 \mathrm{AU}$, respectively.

Figure $6 \mathrm{~B}$ shows the fluorescence intensity of microwaved and untreated milk EV. The average fluorescence intensities were $342.43 \pm 1.51$ and $376.73 \pm 1.48 \mathrm{AU}$ for microwaved milk and normal milk, respectively, which indicates that the total RNA concentration in normal milk EV was higher than that in microwaved milk EV.

\section{DISCUSSION}

Milk is a complex food containing a balance of water, minerals, vitamins, proteins, carbohydrates, and lipids. In addition to these components, milk is a rich source of miRNA, which are relatively stable under different household storage conditions (Baddela et al., 2016)

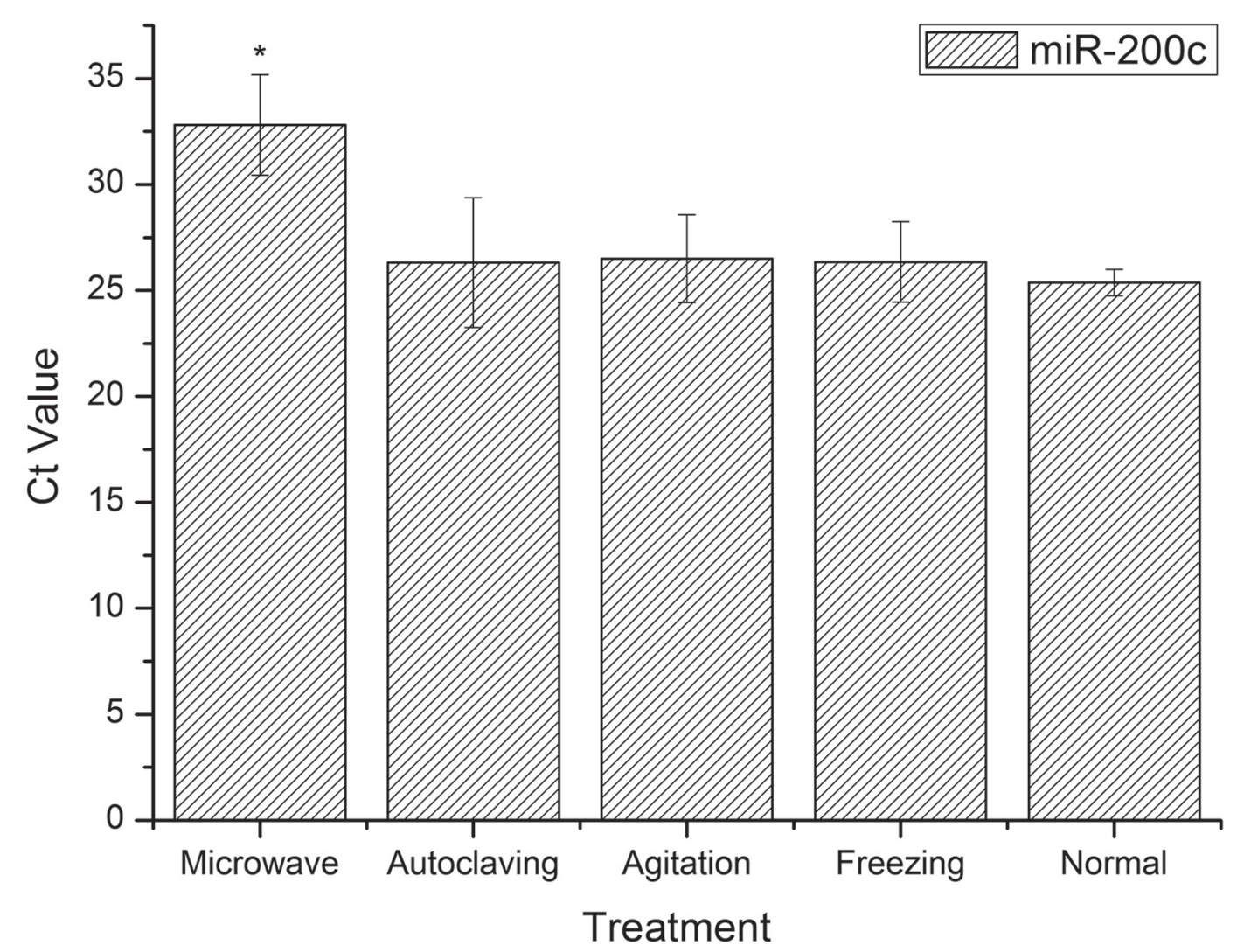

Figure 1. The mean cycle threshold $(\mathrm{Ct})$ value of miR-200c in each milk sample after different treatments. Error bars represent standard deviation. ${ }^{*} P<0.05$. 
and degradative conditions because they are protected by EV in the milk (Hata et al., 2010; Izumi et al., 2012). We confirmed the presence of miRNA after milk processing but detected a loss of miR-200c after a microwave treatment. According to a study by Chen et al. (2010b), miR-200c is 1 of 7 milk-specific miRNA that could serve as a novel indicator and possibly as a new standard for the quality control of raw milk and milk-related commercial products; thus, it is used for reflecting the effect of microwaving on milk miRNA. Moreover, miR-21 is an oncomiR, which is a microRNA that could promote cancer (Feng and Tsao, 2016) and is related to different kinds of cancer, such as malignant melanoma (Melnik, 2015b; Shi, 2016), prostate cancer (Gao et al., 2016), and hepatocellular carcinoma (Jiang et al., 2016). In another study, miR-21 was a consistent component of cow milk and human breast milk and appeared to play a key role in the mechanistic target of rapamycin complex 1 (mTORC1) signaling (Melnik, 2015a). Recently, a review revealed that miR-29 was also involved in that signaling pathway (Melnik et al., 2013). By comparing in the microRNA database, bo- vine milk microRNA miR-21, miR-200c, and miR-29b have the same nucleotide sequence as human microRNA (fata from miRBase Release 21; http://www.mirbase .org/), so we regarded them as our targets.

Howard et al. (2015) did not detect a significant decrease in miR-200c, but we did (Figure 3). Conversely, those authors saw a decrease in miR-29b by $40 \%$ (Howard et al., 2015), but the decrease was not significantly lower in our study. These differences may be due to the background of the cows whose milk was studied or because different RNA extraction and detection methods were used (Izumi et al., 2012). Despite the differences between studies, Howard et al. (2015) speculated that the loss of miRNA was due to the disruption of EV.

Though it appeared in Figure 3B that the milk EV were destroyed by microwaving, the RNases in the milk or the air take time to degrade the RNA molecules. Thus, the mean $\mathrm{Ct}$ value increased $30 \mathrm{~min}$ after the microwave treatment. The belief that microwaving not only destroys nutritional components, such as whey proteins, but also results in DNA damage is widespread (Dehghan et al., 2012; Musto et al., 2014). Therefore,

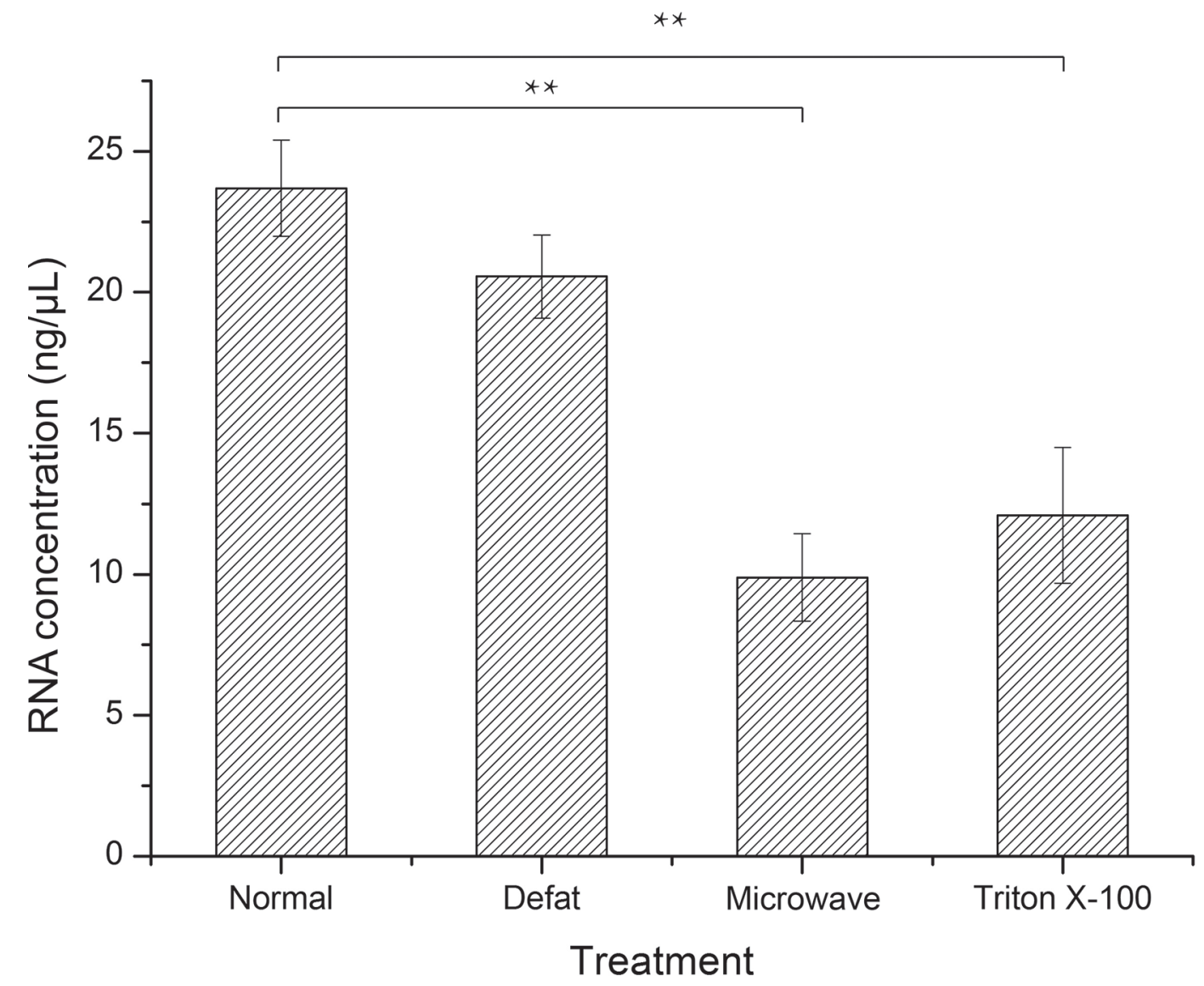

Figure 2. Concentrations of RNA in different milk samples. Normal = untreated milk; Defat = defatted milk; Microwave $=$ microwaved milk; Triton X-199 = milk treated with Triton X-100 (Sangon Co. Ltd., Shanghai, China). Error bars represent standard deviation. 
A
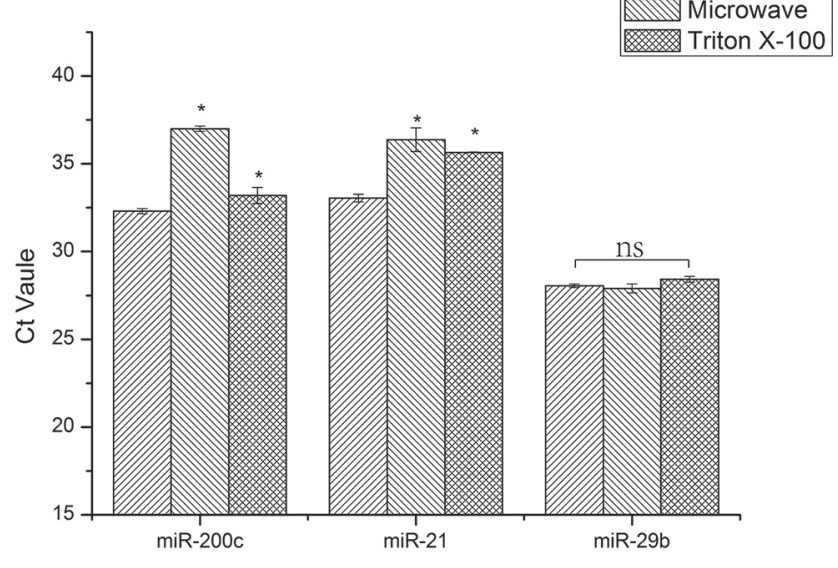

B
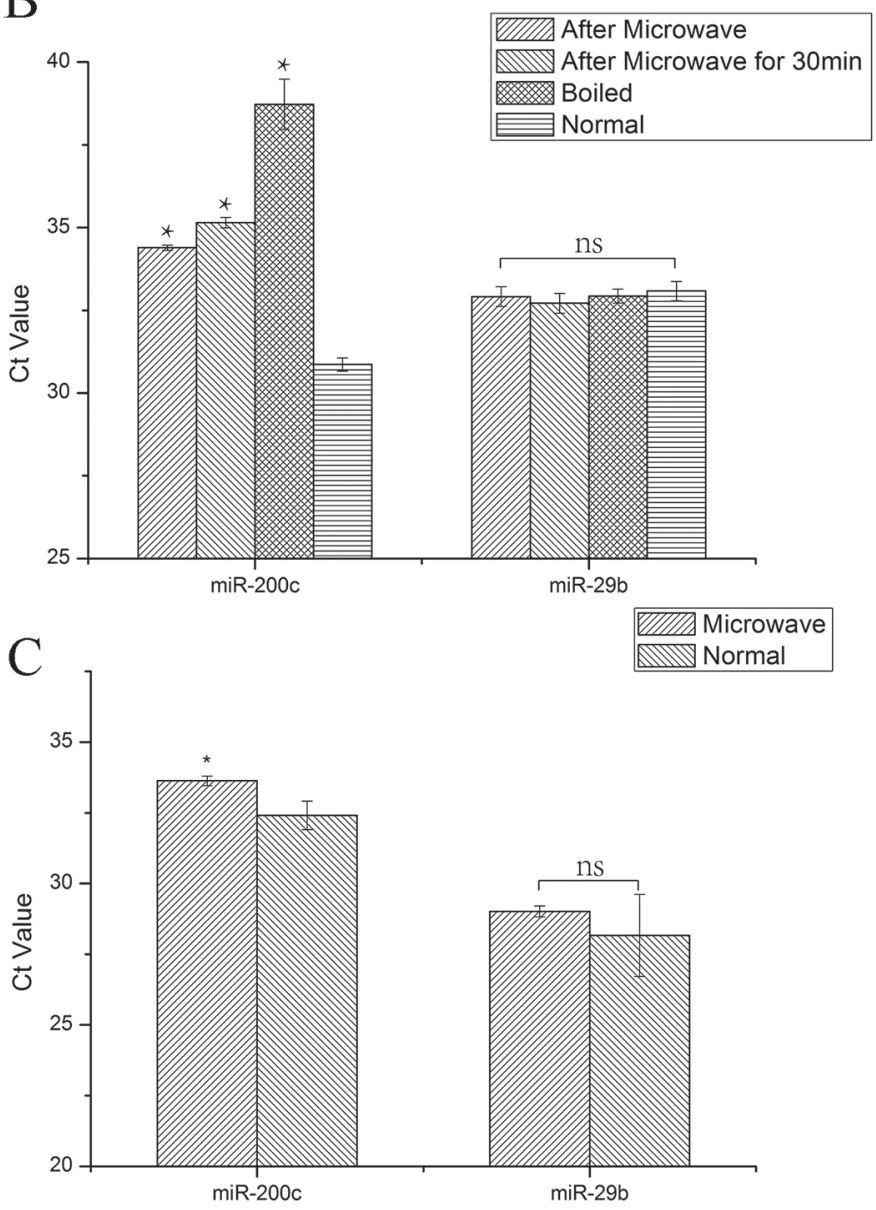

Figure 3. The effect of microwaving on milk (A and B) and milk extracellular vesicle $(\mathrm{C})$ miRNA concentrations. Error bars represent standard deviation. ${ }^{*} P<0.05 ;{ }^{*} P<0.01$.

we could not exclude the possibility that microwaves directly damage RNA. To verify whether microwaves disrupt the integrity of the EV, resulting in a decrease in the amount of miRNA, acridine orange staining was used to measure the fluorescence intensity of RNA in milk-derived EV. Acridine orange is a selective metachromatic dye generally used to stain acidic vacuoles (lysosomes, endosomes, and autophagosomes), RNA, and DNA in living cells (Darzynkiewicz, 1990; Fan et al., 2006). Acridine orange can easily penetrate biological membranes and emits a yellow fluorescence when it binds to RNA. Our results (Figure 6A) showed that when the milk was diluted, the fluorescence intensity of the EV isolated from the diluted samples decreased as the dilution ratio increased. It seems that the fluorescence intensity is positively correlated with the RNA content of the EV. Conversely, a decrease in the fluorescence intensity occurred after microwave treatment, which suggested that microwaving was responsible for the reduction of RNA in the EV. To the best of our knowledge, the current study is the first to use acridine orange dye to determine if changes in the RNA content of milk occur after processing. We could combine the acridine orange straining data with a miRNA expression profile analysis by $\mathrm{qPCR}$ to demonstrate the effect of microwaving on the RNA in the milk-derived EV.

Few investigations have been conducted on EV after milk processing because of the challenges and limitations of the tracking instruments. Our findings extend prior research by determining the microstructure and the size distribution of the EV after a microwave treatment. Our scanning electron microscopy and DLS results indicated that 2 populations of particles of different sizes existed. All of the particles visualized by scanning electron microscopy had a morphology with diameters of $21.67 \pm 6.41$ and $138.47 \pm 21.80 \mathrm{~nm}$. The sizes of particles indicated by DLS were approximately 22.14 and $147.50 \mathrm{~nm}$, which agrees with the scanning electron microscopy results. Strikingly, Vickers et al. (2015) reported that high-density lipoproteins (HDL) transported endogenous miRNA and delivered them to recipient cells with functional targeting capabilities. It is known from the literature that exosomes, which have a density similar to HDL, are significantly larger in size than HDL (10-12 nm; Vickers et al., 2015). Their similar density makes it impossible to separate the HDL from exosomes (Vickers et al., 2015). It is therefore possible that HDL was also purified in our milk samples, delivered the miRNA (such as miR-29b), and protected them from the harsh conditions. Additionally, modifications of the lipid fraction have not been found in milk processed by microwaving $(650 \mathrm{~W})$ for 90 s (Rodríguez-Alcalá et al., 2014), indicating that lipids might be more stable than other components in milk and thus avoid disruption by microwaving.

Overall, we confirmed that microwaves damaged the miRNA in milk-derived EV due to the disruption of $\mathrm{EV}$ by determining the miRNA expression and RNA 


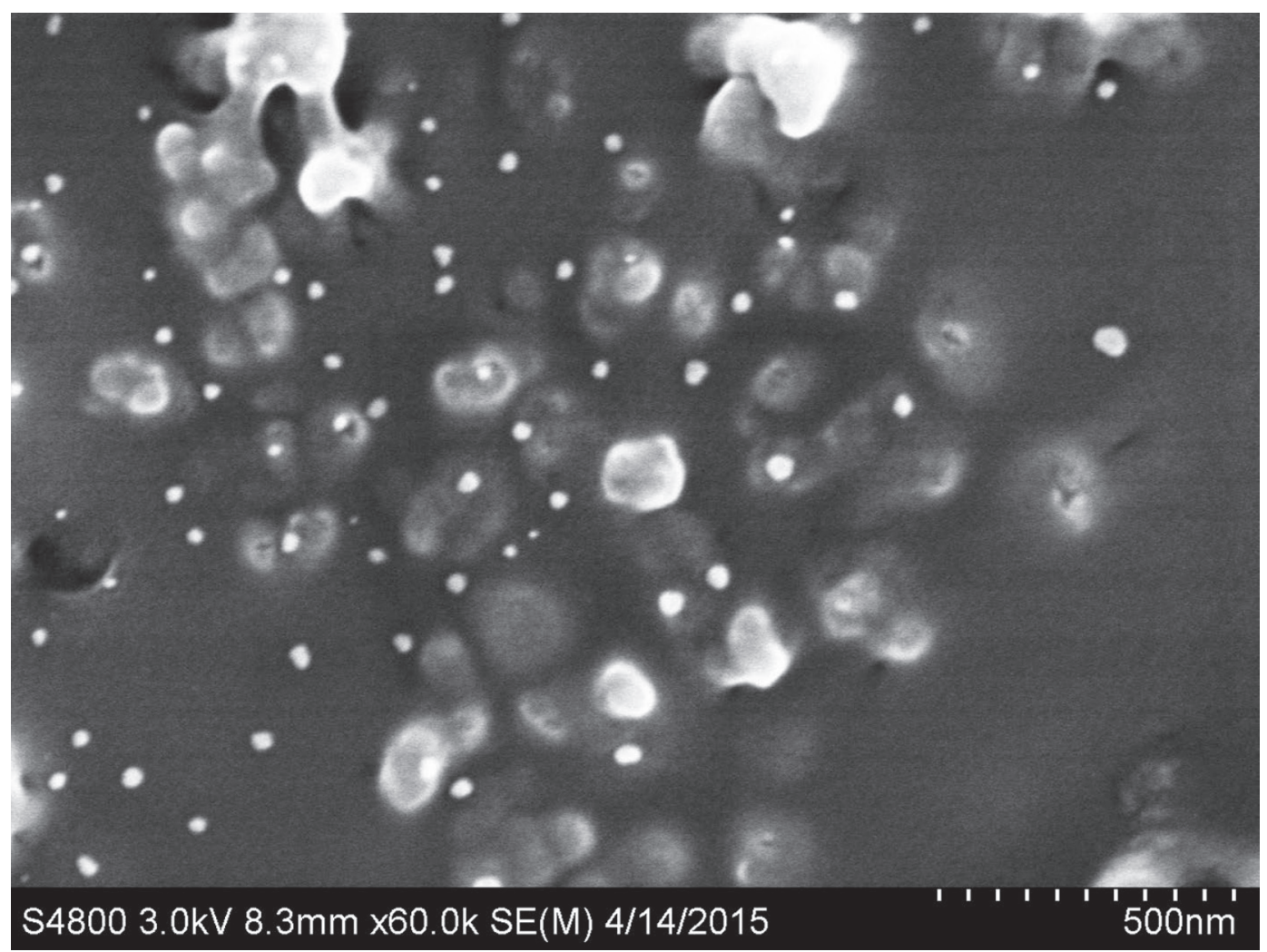

Figure 4. Scanning electron microscopy results of the milk extracellular vesicles.

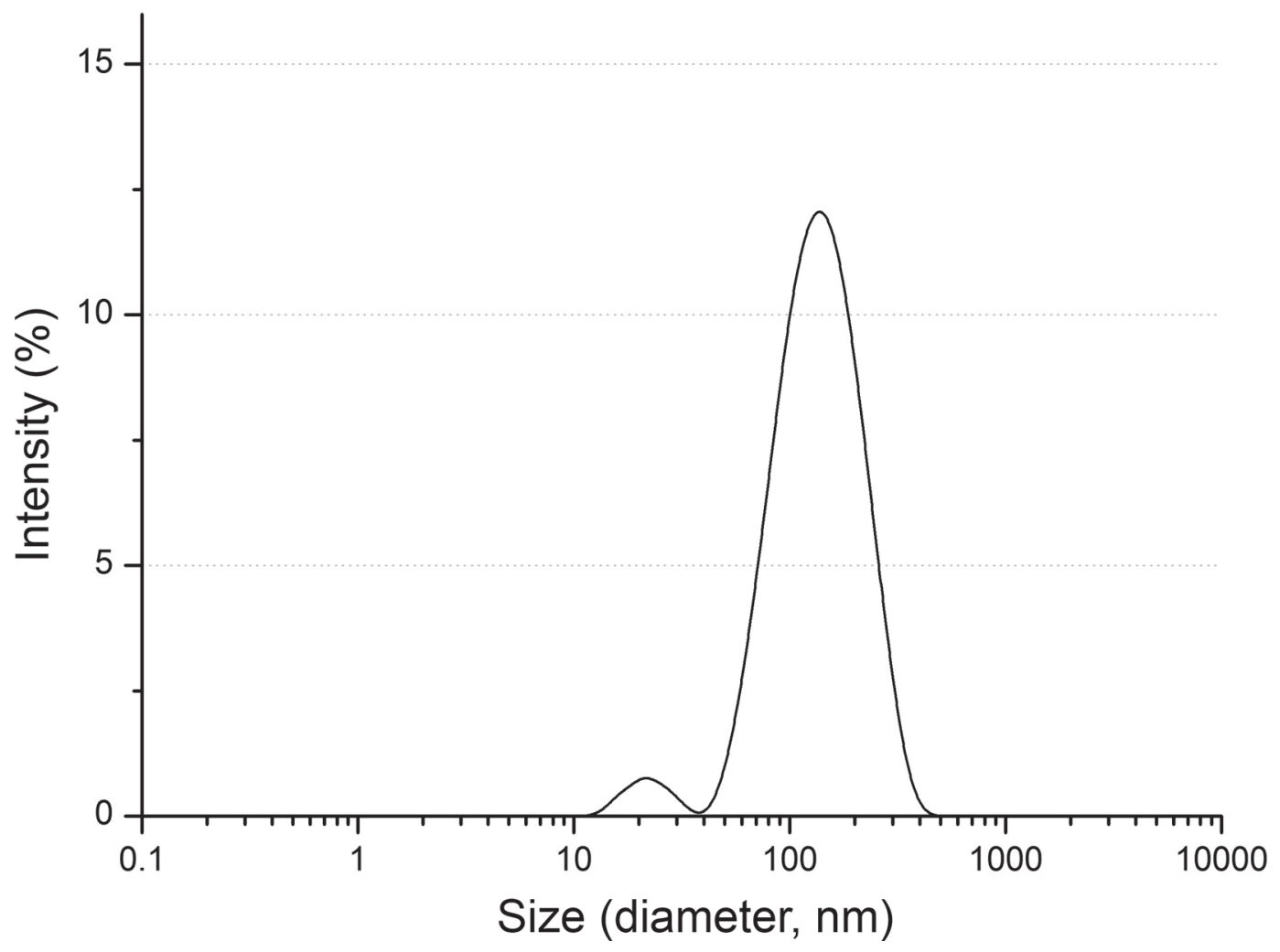

Figure 5. Dynamic light scattering results of milk extracellular vesicles. 
A

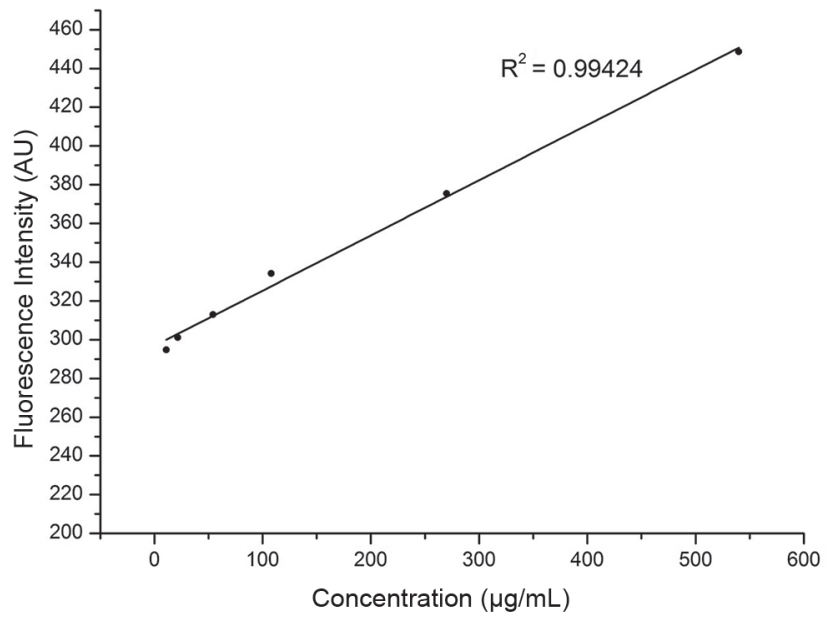

B

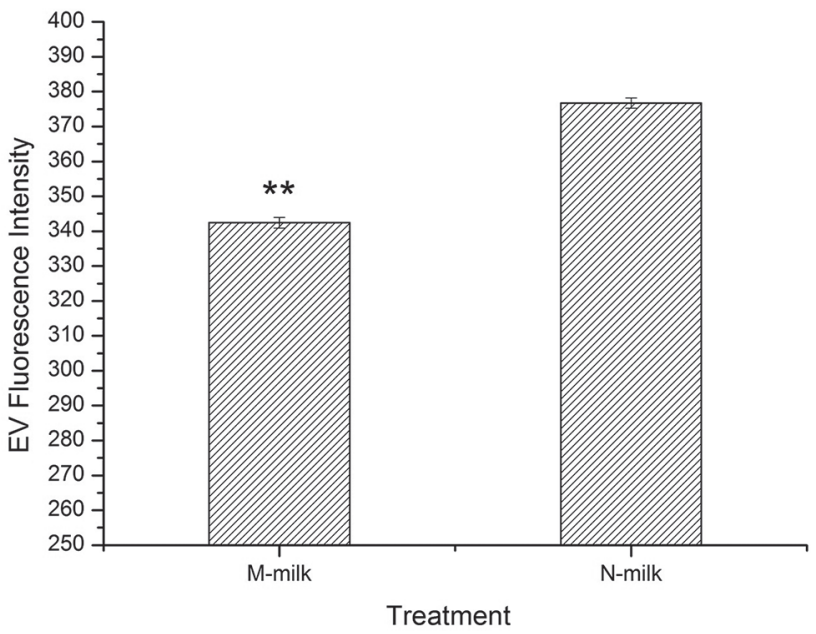

Figure 6. Acridine orange staining of milk extracellular vesicles $(\mathrm{EV})$. Error bars represent standard deviation. ${ }^{* *} P<0.01 . \mathrm{M}=$ microwaved; $\mathrm{N}=$ normal.

content. We also established an effective method for analyzing the RNA content of milk-derived EV, which positively correlated with the $\mathrm{qPCR}$ results. In addition to the experiments on miRNA, we characterized the effects of microwave heating on EV via scanning electron microscopy and DLS. Collectively, our study offers a new explanation of the effect of microwaving on miRNA in the presence of $\mathrm{EV}$ and provides evidence for a strong relationship between miRNA and EV in milk.

More importantly, a few statistical studies have shown that high milk intake may increase the mortality of cancers (Song et al., 2013, Duarte-Salles et al., 2014) and overall mortality (Michaëlsson et al., 2014). We hope that our results will contribute to improvements in milk processing and a healthy human diet in the future. Future research and investigation are still necessary to verify the phenomena discussed in this study.

\section{ACKNOWLEDGMENTS}

This work was supported by the National Natural Science Foundation of China (No. 21476176), the National Key Technology R\&D Program of China (No. 2015BAD16B01), the National High Technology Research and Development Program of China (863 Program, No. 2015AA021002), and the International Science and Technology Cooperation Programs of Anhui, China (No. 1503062006).

\section{REFERENCES}

Baddela, V. S., V. Nayan, P. Rani, S. K. Onteru, and D. Singh. 2016. Physicochemical biomolecular insights into buffalo milk-derived nanovesicles. Appl. Biochem. Biotechnol. 178:544-557.

Baier, S. R., C. Nguyen, F. Xie, J. R. Wood, and J. Zempleni. 2014. MicroRNAs are absorbed in biologically meaningful amounts from nutritionally relevant doses of cow milk and affect gene expression in peripheral blood mononuclear cells, HEK-293 kidney cell cultures, and mouse livers. J. Nutr. 144:1495-1500.

Boon, R. A., K. Iekushi, S. Lechner, T. Seeger, A. Fischer, S. Heydt, D. Kaluza, K. Treguer, G. Carmona, A. Bonauer, A. J. G. Horrevoets, N. Didier, Z. Girmatsion, P. Biliczki, J. R. Ehrlich, H. A. Katus, O. J. Muller, M. Potente, A. M. Zeiher, H. Hermeking, and S. Dimmeler. 2013. MicroRNA-34a regulates cardiac ageing and function. Nature 495:107-110.

Calin, G. A., and C. M. Croce. 2006. MicroRNA signatures in human cancers. Nat. Rev. Cancer 6:857-866.

Chandrasekaran, S., S. Ramanathan, and T. Basak. 2013. Microwave food processing - A review. Food Res. Int. 52:243-261.

Chen, T., Q.-Y. Y. Xi, R.-S. S. Ye, X. Cheng, Q.-E. E. Qi, S.-B. B. Wang, G. Shu, L.-N. N. Wang, X.-T. T. Zhu, Q.-Y. Y. Jiang, and Y.-L. L. Zhang. 2014. Exploration of microRNAs in porcine milk exosomes. BMC Genomics 15:100.

Chen, X., G. Chao, L. Haijin, H. Lei, S. Qi, D. Yanye, T. Chunliang, G. Shengpu, D. Hailin, G. Danping, H. Xiaoyun, Z. Shujian, L. Liang, Z. Lin, Y. Qiao, Z. Junfeng, Z. Ke, and Z. Chen-Yu. 2010a. Identification and characterization of microRNAs in raw milk during different periods of lactation, commercial fluid, and powdered milk products. Cell Res. 20:1128-1137.

Chen, X., C. Gao, H. Li, L. Huang, Q. Sun, Y. Dong, C. Tian, S. Gao, H. Dong, D. Guan, X. Hu, S. Zhao, L. Li, L. Zhu, Q. Tan, J. Zhang, K. Zen, and C.-Y. Zhang. 2010b. Identification and characterization of microRNAs in raw milk during different periods of lactation, commercial fluid, and powdered milk products. Cell Res. $20: 1128-1137$.

Darzynkiewicz, Z. 1990. Differential staining of DNA and RNA in intact cells and isolated cell nuclei with acridine orange. Methods Cell Biol. 33:285-298.

Dehghan, A., J. Jamalian, A. Farahnaky, G. Mesbahi, and M. Moosavi-Nasab. 2012. The effect of microwave pasteurization on some physical and chemical characteristics of milk. Int. J. Food Eng. $8: 1-12$.

Duarte-Salles, T., V. Fedirko, M. Stepien, A. Trichopoulou, C. Bamia P. Lagiou, A. Lukanova, E. Trepo, K. Overvad, A. Tjonneland, J. Halkjaer, M.-C. Boutron-Ruault, A. Racine, C. Cadeau, T. Kuehn, K. Aleksandrova, D. Trichopoulos, K. Tsiotas, P. Boffetta, D. Palli, V. Pala, R. Tumino, C. Sacerdote, S. Panico, H. B. Buenode-Mesquita, V. K. Dik, P. H. Peeters, E. Weiderpass, I. T. Gram, A. Hjartaker, J. Ramon Quiros, A. Fonseca-Nunes, E. MolinaMontes, M. Dorronsoro, C. Navarro Sanchez, A. Barricarte, B. Lindkvist, E. Sonestedt, I. Johansson, M. Wennberg, K.-T. Khaw, N. Wareham, R. C. Travis, I. Romieu, E. Riboli, and M. Jenab. 2014. Dairy products and risk of hepatocellular carcinoma: The European Prospective Investigation into cancer and nutrition. Int. J. Cancer 135:1662-1672. 
Esquela-Kerscher, A., and F. J. Slack. 2006. Oncomirs-MicroRNAs with a role in cancer. Nat. Rev. Cancer 6:259-269.

Fan, C. D., W. W. Wang, B. X. Zhao, S. L. Zhang, and J. Y. Miao. 2006. Chloroquine inhibits cell growth and induces cell death in A549 lung cancer cells. Bioorganic Med. Chem. 14:3218-3222.

Feng, Y.-H., and C.-J. Tsao. 2016. Emerging role of microRNA-21 in cancer. Biomed. Rep. 5:395-402.

Gao, Y., Y. Guo, Z. Wang, Z. Dai, Y. Xu, W. Zhang, Z. Liu, and S. Li. 2016. Analysis of circulating miRNAs 21 and 375 as potential biomarkers for early diagnosis of prostate cancer. Neoplasma 63:623-628.

Gu, Y., L. Mingzhou, W. Tao, L. Yan, Z. Zhijun, W. Xiaoyan, Z. Qi, C. Lei, L. Qiulei, H. Zhiping, C. Xiaohui, G. Jianjun, G. Xiaolian, L. Xuewei, and L. Xuebin. 2012. Lactation-related microRNA expression profiles of porcine breast milk exosomes. PLoS One 7:e43691.

Hata, T., M. Kosuke, N. Hajime, Y. Yasunari, M. Tsukasa, and A. Naohito. 2010. Isolation of bovine milk-derived microvesicles carrying mRNAs and microRNAs. Biochem. Biophys. Res. Commun. 396:528-533.

Howard, K. M., R. Jati Kusuma, S. R. Baier, T. Friemel, L. Markham, J. Vanamala, and J. Zempleni. 2015. Loss of miRNAs during processing and storage of cow's (Bos taurus) milk. J. Agric. Food Chem. 63:588-592.

Izumi, H., N. Kosaka, T. Shimizu, K. Sekine, T. Ochiya, and M. Takase. 2012. Bovine milk contains microRNA and messenger RNA that are stable under degradative conditions. J. Dairy Sci. 95:4831-4841.

Izumi, H., K. Nobuyoshi, S. Takashi, S. Kazunori, O. Takahiro, and T. Mitsunori. 2014. Time-Dependent Expression Profiles of microRNAs and mRNAs in Rat Milk Whey. PLoS One 9:e88843.

Jiang, J., P. Yang, Z. Guo, R. Yang, H. Yang, F. Yang, L. Li, and B. Xiang. 2016. Overexpression of microRNA-21 strengthens stem cell-like characteristics in a hepatocellular carcinoma cell line. World J. Surg. Oncol. 14:278.

Lee, R. C., and V. Ambros. 2001. An extensive class of small RNAs in Caenorhabditis elegans. Science 294:862-864.

Lee, R. C., R. L. Feinbaum, and V. Ambros. 1993. The C. elegans heterochronic gene lin- 4 encodes small RNAs with antisense complementarity to lin-14. Cell 75:843-854.

Lu, M., Q. Zhang, M. Deng, J. Miao, Y. Guo, W. Gao, and Q. Cui. 2008. An analysis of human microrna and disease associations. PLoS One 3:e3420.

Melnik, B. C. 2015a. Milk-A nutrient system of mammalian evolution promoting mTORC1-dependent translation. Int. J. Mol. Sci. 16:17048-17087

Melnik, B. C. 2015b. MiR-21: An environmental driver of malignant melanoma? J. Transl. Med. 13:202

Melnik, B. C., S. M. John, and G. Schmitz. 2013. Milk is not just food but most likely a genetic transfection system activating mTORC1 signaling for postnatal growth. Nutr. J. 12:103

Michaëlsson, K., A. Wolk, S. Langenskiold, S. Basu, E. L. Warensjo, H. Melhus, and L. Byberg. 2014. Milk intake and risk of mortality and fractures in women and men: Cohort studies. BMJ 349:g6015.
Mrvar-Brecko, A., V. Sustar, V. Jansa, R. Stukelj, R. Jansa, E. Mujagić, P. Kruljc, A. Iglic, H. Hägerstrand, and V. Kralj-Iglic. 2010. Isolated microvesicles from peripheral blood and body fluids as observed by scanning electron microscope. Blood Cells Mol. Dis. 44:307-312.

Musto, M., D. Faraone, F. Cellini, and E. Musto. 2014. Changes of DNA quality and meat physicochemical properties in bovine supraspinatus muscle during microwave heating. J. Sci. Food Agric. 94:785-791.

Pieters, B. C. H., O. J. Arntz, M. B. Bennink, M. G. A. Broeren, A. P. M. van Caam, M. I. Koenders, P. van Lent, W. B. van den Berg, M. de Vries, P. M. van der Kraan, and F. A. J. van de Loo. 2015. Commercial cow milk contains physically stable extracellular vesicles expressing immunoregulatory TGF-beta. PLoS One 10:e0121123.

Rodriguez, A., E. Vigorito, S. Clare, M. V. Warren, P. Couttet, D. R. Soond, S. van Dongen, R. J. Grocock, P. P. Das, E. A. Miska, D Vetrie, K. Okkenhaug, A. J. Enright, G. Dougan, M. Turner, and A. Bradley. 2007. Requirement of bic/microRNA-155 for normal immune function. Science 316:608-611.

Rodríguez-Alcalá, L. M., L. Alonso, and J. Fontecha. 2014. Stability of fatty acid composition after thermal, high pressure, and microwave processing of cow milk as affected by polyunsaturated fatty acid concentration. J. Dairy Sci. 97:7307-7315.

Salazar-Gonzalez, C., M. Fernanda San Martin-Gonzalez, A. LopezMalo, and M. E. Sosa-Morales. 2012. Recent studies related to microwave processing of fluid foods. Food Bioproc. Techol. 5:31-46.

Shi, J. 2016. Considering exosomal miR-21 as a biomarker for cancer. J. Clin. Med. 5:42.

Sokolova, V., A.-K. K. Ludwig, S. Hornung, O. Rotan, P. A. Horn, M. Epple, and B. Giebel. 2011. Characterisation of exosomes derived from human cells by nanoparticle tracking analysis and scanning electron microscopy. Colloids Surf. B Biointerfaces 87:146-150.

Song, Y., J. E. Chavarro, Y. Cao, W. Qiu, L. Mucci, H. D. Sesso, M. J. Stampfer, E. Giovannucci, M. Pollak, S. Liu, and J. Ma. 2013. Whole milk intake is associated with prostate cancer-specific mortality among US male physicians. J. Nutr. 143:189-196.

Valadi, H., E. Karin, B. Apostolos, S. Margareta, J. L. James, and O. L. Jan. 2007. Exosome-mediated transfer of mRNAs and microRNAs is a novel mechanism of genetic exchange between cells. Nat. Cell Biol. 9:654-659.

van der Pol, E., A. N. Boing, P. Harrison, A. Sturk, and R. Nieuwland 2012. Classification, functions, and clinical relevance of extracellular vesicles. Pharmacol. Rev. 64:676-705.

Vickers, K. C., B. T. Palmisano, B. M. Shoucri, R. D. Shamburek, and A. T. Remaley. 2015. MicroRNAs are transported in plasma and delivered to recipient cells by high-density lipoproteins. Nat. Cell Biol. 13:423-433.

Weber, J. A., D. H. Baxter, S. Zhang, D. Y. Huang, K. H. Huang, M. J. Lee, D. J. Galas, and K. Wang. 2010. The microRNA spectrum in 12 body fluids. Clin. Chem. 56:1733-1741. 